\title{
DERECHO AMBIENTAL: ALGUNAS REFLEXIONES DESDE EL DERECHO ADMINISTRATIVO
}

\author{
Blanca Lozano Cutanda \\ Catedrática de Derecho Administrativo \\ Universidad del País Vasco
}

\begin{abstract}
RESUMEN
El presente trabajo se dedica al análisis del surgimiento y desarrollo del derecho ambiental, con especial atención a España. Se trata de derecho muy reciente, pues surge en la segunda mitad del siglo xx como respuesta a la toma de conciencia internacional sobre la necesidad de frenar el proceso de deterioro de los sistemas de la biosfera que sirven de soporte a la vida. Su desarrollo ha sido, sin embargo, espectacular, y hoy es un sector del ordenamiento dotado de principios propios (el nuevo principio doctrinal de no regresión o cláusula standstill empieza a abrirse paso en la jurisprudencia constitucional como alternativa o refuerzo del de desarrollo sostenible), y que incide en todos los demás ámbitos jurídicos. En este estudio se repasan los principales problemas y desafíos que plantea actualmente la protección jurídica del medio ambiente y se avanzan algunas propuestas para mejorar la calidad de las leyes ambientales y hacer más efectiva su aplicación.
\end{abstract}

Palabras clave: derecho ambiental; cambio climático; Unión Europea; desarrollo sostenible; principio de no regresión; cláusula standstill; impuestos ecológicos; gobernanza ambiental; justicia ambiental.

\begin{abstract}
The work explores the inception and development of environmental law, with a particular focus on Spain. This is a relatively new area of law which emerged during the second half of the 20th century in response to international awareness on the need to curb the deterioration of the biosphere systems that sustain life. Its progression, however, has been remarkable, so much so that today it is a legal system endowed with its own principles (the new doctrinal principle of the non-regression is making inroads in constitutional case law as an alternative or reinforcement of sustainable development), and, moreover, impacts all other legal areas. This study examines the main problems and challenges currently faced in the course of the legal protection of the environment and goes on to offer various proposals aimed at improving the quality of environmental laws and making the application of the same more effective.
\end{abstract}

Key words: environmental law; climate change; European Union; environmental principles; sustainable development; non-regression clause; environmental taxes; environmental governance; environmental justice. 


\section{SUMARIO}

I. El ORIGEN Y LA RAZÓN DE SER DE LA REGULACIÓN AMBIENTAL.-II. REPASO A VUELAPLUMA DE LA EVOLUCIÓN DEL DERECHO AMBIENTAL ESPAÑOL.-III. ANÁLISIS Y PROPUESTAS DE MEJORA DE LA LEGISLACIÓN Y DE LA GOBERNANZA AMBIENTALES.

\section{El ORIGEN Y LA RAZÓN DE SER DE LA REGULACIÓN AMBIENTAL}

En 1950, cuando se publicó el número 1 de esta Revista faltaban todavía doce años para que The New Yorker publicara, en tres fascículos, Silent Spring, la obra de Rachel Carlson advirtiendo de los peligros para la salud y el medio ambiente del uso de los pesticidas, cuya destreza literaria consiguió despertar la conciencia ciudadana sobre los peligros de la contaminación. Más allá del mensaje radical del libro contra el uso de los pesticidas químicos — que prendió en la población americana y llevó a la prohibición del DDT en 1972 por la recién creada Agencia de Protección Ambiental (NEPA)_, su capítulo titulado «la obligación de resistir» pone de relieve una realidad incontestable y que explica el origen, relativamente reciente, de la protección jurídica del medio ambiente: "Solo dentro del momento de tiempo representado por el presente siglo, una especie (el hombre) ha adquirido una capacidad significativa para alterar la naturaleza de su mundo».

La sociedad utiliza el derecho para dar una respuesta a los retos y dilemas de cada tiempo histórico. El problema que se aborda con el derecho ambiental es, a decir de los científicos, el de la desestabilización antrópica de la biosfera: como resultado de las fuerzas motrices activadas por la revolución industrial (crecimiento económico, explosión demográfica —en el siglo xx la población humana se triplicó y los demógrafos de Naciones Unidas prevén que alcance los 9.600 millones de personas a finales del presente siglo, uso masivo de las energías fósiles, consumo de masas-), una infinidad de precisiones e impactos ambientales con efecto acumulativo y sinérgico han provocado la desestabilización de las funciones de soporte de la biosfera, y la comunidad científica insiste en que existe el riesgo cierto de un cambio irreversible ${ }^{1}$.

1 Véase A. Olabe Egaña (2016), Crisis climática-ambiental, Barcelona: Galaxia Gutenberg, que resume con maestría el estado de conocimiento científico actual sobre los problemas que amenazan la estabilidad de los distintos subsistemas que sirven de soporte al ecosistema de la Tierra y apunta algunas posibles soluciones. Ese autor cita el estudio llevado a cabo por J. Rocкsтröм et al. (2009), "A safe operating space for humanity», Nature, 461 (7263), págs. 472-475, en el que se identifican y analizan nueve subsistemas ambientales con sus respetivos umbrales de seguridad y se concluye que tres de ellos ya han sobrepasado sus umbrales críticos - la pérdida de diversidad ecológica, la alteración del ciclo del nitrógeno y el cambio 
El derecho ambiental lo podríamos definir hoy como el sistema normativo dirigido a la preservación del entorno humano mediante el control de la contaminación y la garantía de un uso sostenible de los recursos naturales y de los sistemas de la biosfera que sirven de soporte a la vida. Su punto de partida está en la constatación científica y el reconocimiento social de una amenaza muy reciente para el desarrollo humano y carece, por ello, de la tradición histórica de las otras ramas del derecho. Pero aunque nuevo en el panorama jurídico, el derecho ambiental ha experimentado en los últimos cuarenta años una expansión inusitada, un auténtico "desbordamiento» que genera grandes resistencias político-económicas.

La razón última de las resistencias — cuando no rechazo frontal— que suscita el derecho ambiental en buena parte de los actores políticos y de la sociedad tiene, a mi juicio, una explicación metajurídica muy simple: los problemas ambientales se desarrollan sobre escalas temporales mucho más amplias que la vida humana y muchísimo más amplias que los mandatos políticos. Los motivos a corto plazo de los individuos y de las sociedades, en los que predominan las variables económicas puramente egoístas, se imponen sobre los motivos a largo plazo, por lo que la solidaridad intergeneracional se hace difícil. Expresado con el humor de Grouxo Marx: «¿Por qué debería preocuparme por la posteridad? ¿Qué ha hecho la posteridad por mí?». La sociedad es la que manda, y a día de hoy la ciudadanía — española, pero también de cualquier otro país- difícilmente va a refrendar con sus votos la gestión de un gobierno que haya llevado a cabo una excelente protección de los recursos naturales pero cuya política económica haya dado como resultado un importante aumento de las cifras del paro.

En una visión pesimista del problema, habrá que esperar a que los problemas ambientales, en especial los derivados del cambio climático, se manifiesten de forma dramática e impacten directamente sobre el PIB para que los gobernantes se vean obligados a adoptar soluciones drásticas. Así ha ocurrido en nuestro país con la tantas veces anunciada pero nunca evitada «explosión de la burbuja inmobiliaria»: hasta que no se hundió el mercado inmobiliario sobredimensionado, y con él nuestra economía, no se comenzaron a tomar medidas jurídicas eficaces contra el urbanismo desenfrenado y corrupto que impide una ordenación sostenible de nuestro territorio.

climático-, mientras que en otros cuatro - la acidificación de los océanos, la disponibilidad de agua potable, los cambios en los usos del suelo y el ciclo del fósforo-, la intensidad y velocidad de los cambios en curso es tan elevada que previsiblemente pronto se sobrepasarán los umbrales correspondientes; sólo la capa de ozono presenta una trayectoria positiva como consecuencia de la aplicación de los acuerdos internacionales alcanzados en el Protocolo de Montreal (1987). 
Sin embargo, la reacción de la comunidad internacional ante el cambio climático, el más urgente y grave, sin duda, de los problemas ambientales (hasta el punto de reputarse actualmente como una de las amenazas para la seguridad internacional ${ }^{2}$ ), permite abrigar esperanzas. El año 2015 pasará sin duda a la historia del derecho ambiental internacional por el acuerdo alcanzado en diciembre en París en el seno de la Convención Marco sobre Cambio Climático, el denominado Acuerdo de París ${ }^{3}$. Por mucho que los intereses de determinadas corporaciones intenten sembrar dudas y confusión - como se hizo en su día con los efectos del tabaco sobre la salud-, la «verdad incómoda» del cambio climático resulta ya incontestable: es un dato probado que la temperatura media global de la tierra ha aumentado $1,02^{\circ} \mathrm{C}$ desde 1880 , y existe consenso en la comunidad científica internacional sobre que un incremento en más de $2^{\circ}$ en este siglo provocaría efectos irreversibles en el clima de la Tierra y provocaría daños muy graves en el medio ambiente, la economía y la sociedad.

Tras muchos años de infructuosas negociaciones, el acuerdo alcanzado entre Estados Unidos y China hizo posible que en la Conferencia de París se haya establecido por primera vez, de forma clara y en un instrumento jurídicamente vinculante adoptado por representantes de más de ciento setenta países, el objetivo de «mantener el aumento de la temperatura mundial muy por debajo de $2^{\circ} \mathrm{C}$ con respecto a los niveles preindustriales, y proseguir los esfuerzos para limitar este aumento de la temperatura a $1,5^{\circ} \mathrm{C}$, al tiempo que se reconoce la necesidad de «aumentar la capacidad de adaptación a los efectos adversos del cambio climático y promover la resiliencia al clima y un desarrollo con bajas emisiones de gases de efecto invernadero, de un modo que no comprometa la producción de alimentos» (artículo 2) ${ }^{4}$.

2 Por lo que atañe a Europa, el 14 de marzo de 2008 se presentó al Consejo Europeo el documento del Alto Representante y de la Comisión Europea «El Cambio Climático y la Seguridad Internacional», accesible en Internet. Entre las posibles amenazas inminentes para la seguridad europea se incluye el calentamiento de la tierra, se destaca que "puesto que en los países vecinos de la UE se encuentran algunas de las regiones más vulnerables al cambio climático, por ejemplo el norte de África y Oriente Próximo, es posible que en el futuro aumenten la presión migratoria en las fronteras de la Unión Europea y la inestabilidad política y los conflictos. Esto también puede tener un impacto significativo en las rutas de suministro de energía a Europa».

3 Véase A. Lago Candeira, «Agenda 2030 y objetivos de desarrollo sostenible (incluidos los de cambio climático)», contribución al Observatorio de Políticas Ambientales 2016, de próxima publicación por Editorial CIEMAT.

4 A diferencia del Protocolo de Kioto, en este Acuerdo de París no se establecen los objetivos de reducción vinculantes para cada parte sino que se confía a los Estados la fijación de sus «Contribuciones Determinadas a Nivel Nacional» (INDCs por sus siglas en inglés), que deberán presentar cada cinco años con vistas a la consecución de objetivos cada vez más ambiciosos. El Acuerdo apuesta, para corregir la dificultad casi insalvable de adoptar compromisos vinculantes 
Más allá de los compromisos alcanzados, el Acuerdo de París está demostrando ya su efecto dinamizador de la reorientación del mercado hacia lo que se conoce como economía verde: una economía que aboga por la sustitución de los combustibles fósiles por energías renovables y tecnologías con bajas emisiones de carbono y por una reestructuración de las inversiones hacia una gama de sectores que, a la vez que producen réditos económicos, potencian la sostenibilidad, tales como las tecnologías limpias, las energías renovables, los servicios de agua, los vehículos eléctricos, el tratamiento de residuos, la edificación o la agricultura y los bosques sostenibles ${ }^{5}$.

La Unión Europea ha hecho de la protección del medio ambiente y, en especial, de la lucha contra el cambio climático, uno de los elementos centrales de su política, y este empeño, impulsado por los países ecológicamente más comprometidos (como Dinamarca, Suecia, Alemania, Francia y Reino Unido), además de otorgarle un merecido prestigio internacional le ha reportado también réditos económicos, demostrando que es posible un crecimiento verde mediante políticas de sostenibilidad que impulsen la creación de empleo y el fomento de la inversión ${ }^{6}$.

Aunque resulta indudable que la green economy genera ventajas y réditos económicos, la regulación sigue siendo necesaria. Cuando se escriben estas líneas, acaba de aparecer en la prensa la noticia de que la petrolera BP propone, como medida para la lucha contra el cambio climático, que se multiplique por seis el precio de la tonelada de $\mathrm{CO}_{2}$ en el mercado de derechos de emisión de la Unión Europea.

Nos damos así de bruces con uno de los instrumentos jurídicos modernos de regulación con que cuenta el derecho ambiental europeo. El Régimen de Comercio de Derechos de Emisión de la Unión Europea

a nivel internacional, en la transparencia (las INDCs se inscribirán en un registro público) y en la presión que, con base en la información disponible la sociedad civil sobre los gobiernos nacionales («Las Partes deberán rendir cuentas de sus contribuciones determinadas a nivel nacional»).

5 Véase PNUMA (2011), Hacia una economía verde. Guía para el desarrollo sostenible y la erradicación de la pobreza, disponible en: http:/www.unep.org/pdf/green_economy_2011/ GER_Spanish.pdf.

6 Así se explica en el Programa General de acción de la Unión en materia de Medio Ambiente hasta 2020 (aprobado por la Decisión n. ${ }^{\circ}$ 1386/2013/UE, del Parlamento y del Consejo): «en los últimos años, el empleo en los sectores de las tecnologías y servicios medioambientales en la Unión ha crecido en torno al 3 por ciento anual. El mercado mundial para las ecoindustrias se estima en, al menos, un billón de euros, y se prevé que en los próximos diez años llegue casi a duplicarse. Las empresas europeas ya son líderes mundiales en reciclado y eficiencia energética, y hay que estimularlas para que saquen provecho del aumento de la demanda en el mundo, con el apoyo del Plan de Acción sobre Ecoinnovación. Por ejemplo, se espera que el sector europeo de las energías renovables cree, por sí solo, más de 400.000 puestos de trabajo de aquí a 2020. Una bioeconomía sostenible también puede contribuir a un crecimiento inteligente y verde en Europa y, a la vez, beneficiarse de las mejoras de la eficiencia en el uso de recursos". 
(EU ETS) fue introducido, para coadyuvar al logro de los objetivos de reducción de emisiones de gases de efecto invernadero, mediante la Directiva 2002/87/CE y desde entonces, aunque ha sufrido varios avatares y modificaciones, se ha consolidado como un sistema a la vez de regulación e incentivo para la consecución de los objetivos de reducción de emisiones. Este sistema europeo se adscribe a la técnica de los «permisos negociables o derechos de contaminación transmisibles», de origen norteamericano, mediante la que los poderes públicos, como explica la OCDE, «establecen una cantidad de contaminación fija que se puede emitir y permite que el mercado derive el precio» ${ }^{7}$. En el sistema EU ETS $^{8}$, expuesto de forma muy simplificada, a las empresas de los sectores incluidos se les asignan determinados derechos de emisión, con lo que se está creando la escasez necesaria para que exista un mercado, de tal manera que las empresas que mantienen un nivel de emisión por debajo de lo que les permiten sus derechos, pueden vender los derechos excedentarios al precio que determinen la oferta y la demanda imperantes en ese momento; en cambio, las empresas que tienen dificultad para mantenerse por debajo de sus límites de emisión pueden elegir entre tomar medidas para reducir sus emisiones (por ejemplo, invertir en tecnologías más eficientes), comprar los derechos que les faltan al precio del mercado, o una combinación de ambas posibilidades, según lo que les resulte económicamente más interesante.

Ahora bien, ¿por qué es necesario que la UE regule la creación de un mercado secundario de algo, como la contaminación, que carece en absoluto de valor?

En la respuesta a esta pregunta está todo el fundamento de la regulación ambiental, del «derecho ambiental administrativo» en suma. Este sector jurídico es fundamentalmente regulatorio porque también es regulatorio el presupuesto económico en el que se sustenta. La ciencia económica convencional había ignorado, hasta mediados del siglo pasado, la variable ambiental en la toma de decisiones, dado que la naturaleza parecía un proveedor inagotable de recursos naturales y un receptor sin fondo de emisiones y vertidos contaminantes. Pero a medida que los bienes comunes o «libres» empezaron a emitir señales de escasez o deterioro, cada vez más acusadas, científicamente contrastadas y perceptibles (contaminación de ríos y acuíferos; vertidos y emisiones nocivos para la

\footnotetext{
7 Informe El sistema tributario, la innovación y el medio ambiente, 2010, accesible en Internet.

8 Véase, por todos, I. Sáinz Rubiales y S. Anibarro Pérez (2014), Cambio climático y Unión Europea: presente y futuro del mercado europeo de emisiones (estudios de derecho público), Barcelona: Tirant lo Blanch, y T. Parejo NAvAJAs (2015), "Gobernar el cambio climático», en L. Parejo Alfonso (coord.), El derecho ante la innovación y los riesgos derivados del cambio climático, Valencia: Tirant lo Blanch.
} 
salud, acelerada pérdida de biodiversidad y un largo etcétera), se hizo evidente la necesidad de cambiar de modelo.

En este nuevo modelo económico resulta capital el concepto de «externalidades negativas», alumbrado a nivel teórico en 1920 por el economista Albert Cecil Pigou en The Economics of Welfare. La incapacidad del mercado abandonado a sí mismo para proveer a las necesidades humanas se explica así, en términos económicos, por la existencia de costes ambientales que escapan del sistema de precios. Los precios, que sirven de guía a las decisiones de consumidores y productores, no reflejan los costes y beneficios derivados del uso del medio ambiente, dando lugar a las denominadas externalidades negativas. Cuando un agente económico realiza una actividad de producción o consumo para su propio beneficio, no tiene que soportar los costes ambientales que esta actividad provoca, pues, al no reflejarse en los precios, estos costes o efectos negativos son "externos» a la propia actividad y repercuten en el conjunto de la sociedad. Por ello, el agente económico, llevado por el objetivo de maximización de la utilidad o beneficio individual que rige sus decisiones, tenderá a explotar/deteriorar al máximo el medio ambiente, más allá de lo que resulta racional para la preservación futura del ecosistema que sirve de soporte a la vida.

Para introducir y hacer respetar el valor de la preservación del ecosistema en una biosfera finita es preciso, por tanto, que intervengan los poderes públicos prohibiendo o limitando determinadas actividades contaminantes o destructoras del medio, y procurando, en otras, la internalización de los costes ambientales: que el agente económico pague por la contaminación o daño ambiental que genera, incorporando así esta variable a sus costes de producción. Los impuestos ambientales y los permisos negociables son dos técnicas utilizadas para llevar a cabo esta internalización, aunque operan de forma muy distinta: mientras los impuestos fijan el precio del contaminante y luego permiten que el mercado determine la tasa de contaminación, los permisos negociables, como hemos expuesto, establecen la cantidad máxima de contaminación que se puede emitir (medida en toneladas de $\mathrm{CO}_{2}$ en el EU ETS), y luego dejan que el mercado derive el precio.

El derecho ambiental es tan complejo y multinivel como lo son los propios problemas ambientales y no es sólo, cierto, regulación, pero la mayor parte de sus normas se adscriben a las técnicas conocidas en la terminología anglosajona como de command and control, mediante las que se establecen límites o prohibiciones para la defensa de bienes colectivos o intereses de naturaleza difusa que no tienen un titular determinado (la calidad del aire o del agua o los hábitats naturales y las espe- 
cies silvestres), y se condiciona el ejercicio de determinadas actividades o proyectos a su compatibilidad con la preservación del medio.

\section{REPASO A VUELAPLUMA DE LA EVOLUCión DEL DERECHO AMBIENTAL ESPAÑOL}

La consolidación de un sector del ordenamiento jurídico alrededor del núcleo conceptual del medio ambiente es un proceso histórico que se inicia cuando las normas protectoras de algunos recursos naturales especialmente valiosos para las actividades humanas, fundamentalmente aguas, montes y minas, adquieren la entidad suficiente como para singularizarse y configurar un sistema normativo propio.

Pero ya antes de que las normas protectoras se definieran como tales, la necesidad de organizar y distribuir el uso y explotación de unos recursos limitados y de asegurar su pervivencia está en el origen de su progresiva intervención por el Estado y en la declaración como bienes demaniales de algunos de ellos. Así, en los primeros quince años de esta Revista, entre 1950 y 1965, encontramos ya diversos artículos dedicados a los recursos naturales, que tratan cuestiones tales como la regulación de la concesión minera, el deslinde de los montes públicos, la demanialización y la gestión de las aguas públicas o el deslinde de la zona marítimo-terrestre ${ }^{9}$.

En las regulaciones de estos recursos naturales y, muy especialmente en la relativa a las aguas superficiales, late una preocupación ambiental avant la lettre por ordenar el aprovechamiento y evitar la sobreexplotación a que conduce el interés individual de maximizar el beneficio de un recurso limitado: el dilema conocido hoy como «tragedia de los comunes». Los "principios de la buena administración», decía la Exposición de Motivos del Proyecto que sirvió de base para la Ley de Aguas de $1866^{10}$, exigen «la intervención del Poder Público en el disfrute y aprovechamiento de aquellas cosas que, aunque son de uso común, no bastan para el consumo de todos. La sociedad no puede abandonarlas al interés o la codicia individual sin ocasionar grandes perturbaciones en el orden público; y el fomento de la riqueza exige por otra parte que se dé la pre-

\footnotetext{
9 Véanse, entre otros, J. L. Villar Palasí, "Naturaleza y regulación de la concesión minera», Revista de Administración Pública, 1, págs. 79-116; E. SERRANo GuIRAdo (1950), «El procedimiento administrativo en los deslindes de montes públicos», Revista de Administración Pública, 2, págs. 109-130; F. Alonso Moya (1951), "Sobre las aguas de dominio público y de dominio privado", Revista de Administración Pública, 4, págs. 29-74; S. Martín-Retortillo (1960), «La elaboración de la Ley de Aguas de 1866», Revista de Administración Pública, 32, págs. 11-54, e I. Gonzalo RodRíGuEz (1964), «Doctrina del Tribunal Supremo sobre el deslinde de la zona marítimo-terrestre», Revista de Administración Pública, 43, págs. 237-250.

10 Alonso Moya (1951: 30-31).
} 
ferencia a aquellos aprovechamientos que más puedan contribuir a ella, distribuyendo esos bienes comunes con la misma economía y acierto con que un prudente padre de familia distribuye los suyos». Hoy, la conexión existente entre la protección constitucional del medio ambiente y la demanialización de una categoría de bienes sido reconocida expresamente por el Tribunal Constitucional respecto del dominio público marítimo-terrestre, reiterando el «nexo teleológico que une a los arts. 45 y 132 CE» (STC 233/2015 que cita, en este sentido, la STC 227/1988).

En 1964, una crónica administrativa da esta Revista daba cuenta de una reforma del Reglamento de actividades molestas, insalubres, incómodas o peligrosas que había sido aprobado por Decreto de 30 de noviembre de 1961. Este Reglamento, coloquialmente conocido como «RAMINP», tenía por objeto evitar que los establecimientos, actividades o industrias «produzcan incomodidades, alteren las condiciones normales de salubridad e higiene del medio ambiente y ocasionen daños a las riquezas pública o privada o impliquen riesgos graves para las personas o los bienes». El RAMINP citó así expresamente el «medio ambiente» y en su regulación aplicó, siguiendo la línea ya apuntada por la normativa decimonónica sobre sanidad pública, las técnicas de la prohibición, de la autorización, de la imposición de medidas correctoras y del alejamiento de los núcleos de población de las actividades molestas o insalubres. Sobre este inveterado Reglamento volveremos más adelante.

El primer reconocimiento normativo del medio ambiente como un conjunto integrador de los distintos bienes y recursos que conforman el ecosistema humano lo encontramos en la Exposición de Motivos de la Ley de Protección del Ambiente Atmosférico, de 22 de diciembre de 1972. La fecha es muy significativa pues pocos meses antes, entre el 5 y el 16 de junio de 1972, se celebró en Estocolmo a instancias de las Naciones Unidas la Conferencia Mundial sobre el Medio Humano, más conocida como «Conferencia de Estocolmo». Se trata de un hito muy importante en el derecho internacional, pues por primera vez un foro internacional (la Conferencia contó con la presencia de ciento catorce Estados y un número importante de Organizaciones No Gubernamentales), centra su atención en el medio ambiente como un concepto comprensivo de una defensa global y sistemática de la naturaleza a escala mundial, superándose el utilitarismo y la visión sectorial y regional de los problemas ambientales hasta entonces imperante. El principal fruto de esta primera Cumbre de la Tierra fue la «Declaración de principios para la preservación y mejora del medio humano», conocida como «Declaración de Estocolmo», que contiene veintiséis principios en los que se abordan las principales cuestiones que afectan al medio humano a nivel 
mundial y se sientan los criterios que van a presidir la actuación internacional en este ámbito, auténtica «Carta Magna» de la protección del medio ambiente que marca el punto de partida del derecho ambiental en sentido moderno.

La Exposición de Motivos de la Ley de Protección del Ambiente Atmosférico se declara tributaria de esta toma de conciencia internacional sobre la necesidad de poner coto a la degradación del medio ambiente, cita la reunión de Estocolmo y afirma que «la universalidad del movimiento en favor de una defensa sistemática de la Naturaleza excluye radicalmente toda posible actitud de abstencionismo. El Estado debe asumir una posición activa respecto a estos temas, y con mayor razón en aquellos países, como España, en los que por el grado actual de industrialización no se han alcanzado aún niveles intolerables de degradación ambiental, salvo en casos muy excepcionales». Llama la atención la clarividencia de este texto, en el que se enuncian muchos de los distintos ámbitos sectoriales de actuación que integran actualmente el derecho ambiental, a pesar de que apenas tenían en aquel entonces desarrollo normativo, y se afirma a continuación que todos esos sectores «no son sino aspectos parciales de una política general de múltiples facetas, en buena parte inexploradas», con lo que se afirma el hoy conocido como «carácter horizontal de la política ambiental», que ha cristalizado en la Unión Europea en el principio de integración de la consideración ambiental en las demás políticas comunitarias, expresamente reconocido por el artículo 11 del TFUE.

El derecho ambiental español va a comenzar a desarrollarse a partir de la década de los setenta impulsado por la Conferencia de Estocolmo. A partir de esta primera cumbre de la Tierra, se han venido celebrando conferencias que se conocen, por su periodicidad, como decenales ${ }^{11}$. En estas conferencias decenales se revisan y aprueban los principios y las estrategias tanto para abordar mediante Tratados ambientales específicos los problemas que requieren de una acción a nivel internacional (el cambio climático, el agotamiento de la capa de ozono, el comercio ilegal de especies, la contaminación marina y un largo etcétera) como para promover la actuación coordinada de todos los países en la consecución de los objetivos ambientales.

En el desarrollo y eclosión del derecho ambiental moderno ha desempeñado también un papel fundamental el movimiento ambiental de

11 Hasta el presente: Conferencia de Río de Janeiro sobre Medio Ambiente y Desarrollo de 1992, la Cumbre Mundial sobre Desarrollo Sostenible de Johannesburgo de 2001 — «ío más $10 »$ - y la Conferencia de las Naciones Unidas sobre el Desarrollo Sostenible, celebrada de nuevo en Río de Janeiro, de 2012 — «Río más 20». 
la sociedad civil, canalizado ya sea a través de organizaciones no gubernamentales (ONG), o ya sea a través de partidos ecologistas. Las ONG ambientales se caracterizan por su radicalismo y su combatividad; responden a un movimiento de resistencia civil, dispuesto a salirse de los estrechos márgenes de la acción política tradicional según los postulados de la community organizing ${ }^{12}$. Con esta estrategia logran despertar conciencias y, aunque ciertamente en muchos casos sus denuncias son excesivas (al oponerse, por ejemplo a todas las formas de energía posibles, ya sea porque utilizan combustibles fósiles o generan riesgos, o ya porque afean el paisaje), pero otras veces la historia les ha dado la razón: ¿cuántas veces denunciaron el peligro de las centrales nucleares, siempre negado por la industria, hasta que en 2011 el accidente de Fukushima lo puso en evidencia? Tanto fue así que, tras el accidente, Alemania decidió adelantar el abandono definitivo de la energía nuclear a 2022 porque, como se explica en la web de las representaciones de Alemania en España, este accidente ha puesto de manifiesto «el hecho de que no pueda descartarse por completo un riesgo residual en este tipo de energía».

Las ONG juegan, en especial, un papel fundamental para garantizar un cumplimiento efectivo de la legislación ambiental, acudiendo a los tribunales bien para que fiscalicen y anulen planes y actuaciones públicas o privadas, o bien para obligar a las Administraciones a ejercer las acciones de tutela que el derecho les encomienda (por ejemplo, para instar el inicio del procedimiento para la exigencia de responsabilidad medioambiental previsto en la Ley 26/2007). Ello se explica por la doble cara de la Administración en este ámbito, pues, aunque sea la principal defensora del medio ambiente situado bajo su tutela, puede aparecer también, con frecuencia, como potencial agresora del mismo. Los entes y organismos públicos tienden a defender celosamente sus funciones y, a falta de una auténtica penetración horizontal de la política ambiental, anteponen con frecuencia los intereses que sectorialmente administran a los más amplios y globales que se concitan en la defensa del ambiente $\mathrm{e}^{13}$. De ahí la capital importancia que revisten en este ámbito la transparencia y el desarrollo de los instrumentos de participación, que han

12 «El trabajo del organizador es maniobrar y presentar al establishment como un enemigo público peligroso, al que está justificado atacar [...]. La inmediata reacción histérica del establishment no sólo validará los credenciales de la capacidad del organizador, sino que además lanzará de forma automática una interpelación a la gente normal» (S. ALINSKY, 1971, Rules for Radicals: A Pragmatic Primer for Realistic Radicals, New York: Random House; tomo la cita de la ed. en castellano del proyecto editorial de difusión de textos críticos Traficantes de Sueños, Madrid, 2012).

13 Así lo puso de relieve R. Martín Mateo (1991), Tratado de Derecho Ambiental, Madrid: Trivium, Madrid, vol. 1. 
recibido un fuerte impulso por la firma y ratificación en 2005, por la Unión Europea y sus Estados miembros, del conocido como Convenio de Aarhus ${ }^{14}$, cuya adaptación ha exigido revisar toda la normativa de acceso a la información, participación pública en la toma de decisiones y acceso a la justicia en asuntos ambientales. Favorecer el acceso a la justicia de las ONG ambientales (a las que se reconoce legitimación corporativa para actuar en defensa del medio ambiente y el derecho a la asistencia jurídica gratuita), contribuye poderosamente al cumplimiento de la normativa ambiental, tanto por lo que consiguen como por su efecto preventivo, dado que, como ha puesto de relieve la Comisión Europea, «los responsables en potencia tendrán la tendencia a cumplir sus requisitos para evitar una acción ante los Tribunales que tiene más posibilidad de ocurrir» ${ }^{15}$

Pero volvamos al recorrido por la evolución del derecho ambiental español. Un hito fundamental en su desarrollo fue, sin duda, la constitucionalización en 1978 del «derecho a un medio ambiente adecuado para el desarrollo de la persona» (artículo $45 \mathrm{CE}$ ). El Tribunal Constitucional, en su labor de exégesis del precepto, ha consagrado una concepción amplia del «medio ambiente» garantizado por este precepto, afirmando en su fundamental Sentencia 102/1995 (ponente Rafael Mendizábal Allende), que comprende los recursos naturales pero también «otros elementos que no son naturaleza sino historia, los monumentos, así como el paisaje».

Tras este reconocimiento constitucional, el derecho al medio ambiente captó la atención de la doctrina y fueron sucediéndose las primeras monografías y estudios sobre la materia ${ }^{16}$. Desde entonces, la producción bibliográfica no ha dejado de aumentar y hoy resulta reseñable la importante labor epistémica que lleva a cabo el Observatorio de Polí-

14 Convenio CEPE/ONU sobre acceso a la información, participación pública y acceso a los procedimientos judiciales en materia de medio ambiente, adoptado en la Conferencia Ministerial «Medio Ambiente para Europa» celebrada en la ciudad danesa de Aarhus el 25 de junio de 1998. El Convenio entró en vigor en 2001 y fue ratificado por la entonces Comunidad Europea y por España en 2005.

15 Comunicación de la Comisión sobre «Aplicación del Derecho comunitario de medio ambiente» [COM (1996) 500 final, de 22 de octubre de 1996].

16 El pionero de los estudios ambientales en España fue el profesor Ramón MaRTín Mateo, con su Manual de Derecho Ambiental, cuyas primeras ediciones se remontan a finales de los setenta (actualmente disponible en la $3^{a}$ edición de la editorial Aranzadi, 2005). Entre los primeros manuales que contribuyeron a la sistematización y conocimiento de esta rama jurídica, pueden destacarse también, sin ánimo exhaustivo, las obras de J. Jordano Fraga (1995), La protección del derecho a un medio ambiente adecuado, Barcelona: J. M. Bosch; D. LoPERENA Rota (1998), Los principios del derecho ambiental, Madrid: Civitas; B. Lozano Cutanda (2000), Derecho Ambiental Administrativo, Madrid: Dykinson (actualmente publicado como Tratado de Derecho Ambiental, junto con J. Cruz-Alli y A. Lago Candeira (2015), Madrid: CEF); A. BETANCor (2005), Instituciones de Derecho Ambiental, Madrid: La Ley, y J. Esteve Pardo (2005), Derecho del medio ambiente, Madrid: Marcial Pons. 
ticas Ambientales (el OPAM), coordinado por Fernando López Ramón e integrado por profesores especializados en medio ambiente procedentes de todas las comunidades autónomas y de varios países, que se reúnen y publican cada año un análisis imprescindible de las novedades del derecho ambiental ${ }^{17}$.

El artículo 45 de la Constitución dio lugar a un acalorado debate sobre si el medio ambiente puede o no ser considerado como un auténtico derecho subjetivo. Actualmente, ninguna duda ofrece que el artículo 45 CE enuncia «un principio rector, no un derecho fundamental» (SSTC 82/193; 199/1996; 84/2013 y 233/2015, entre otras), aunque algún destacado autor sigue postulando que en una futura reforma constitucional se le debería reconocer el rango de derecho fundamental ${ }^{18}$.

Ahora bien, como consecuencia de la interpretación que ha alumbrado la jurisprudencia del Tribunal Europeo de Derechos Humanos, avanzada ya, de forma preclara, por el profesor Lorenzo MARTíN-RETORTILlo $^{19}$, se ha dado entrada en el ámbito de protección del Convenio de Roma al derecho a un medio ambiente adecuado, por la vía de lo que este autor denomina la «defensa cruzada de derechos»: si bien el derecho al medio ambiente no aparece reconocido en el Convenio, en la medida en que un ataque al medio ambiente lesiona, limita o pone en grave riesgo el disfrute de determinados derechos sí reconocidos (fundamentalmente el derecho al respeto al domicilio y a la vida privada y familiar del artículo 8, pero también el derecho a la vida del artículo 2), el Tribunal de Estrasburgo podrá entender de las agresiones ambientales determinantes de su lesión. La recepción de esta interpretación por el Tribunal Constitucional y por el Tribunal Supremo permite hoy a los ciudadanos recurrir por la vía preferente y sumaria del recurso de amparo frente a determinados daños medioambientales, fundamental-

17 La idea del proyecto surgió en 2005 en el ámbito de unas jornadas gaditanas y el equipo promotor lo integramos Juan Francisco Alenza, Francisco Delgado Piqueras, Agustín García Ureta, Jesús Jordano Fraga, Demetrio Loperena, Fernando López Ramón, Blanca Lozano Cutanda, Alba Nogueira, Luis Ortega Álvarez, Juan Rosa Moreno, Íñigo Sanz Rubiales y Germán Valencia. La primera edición, coeditada por el Ministerio de Medio Ambiente y Aranzadi, es del año 2006, y desde entonces se publica una anual. La obra puede consultarse on line en la Asociación Ecodes y en la revista Actualidad Jurídica Ambiental. Cumple asimismo destacar la labor que realiza, por lo que respecta al dominio público marítimo-terrestre, el Observatorio del litoral de la Universidad de A Coruña, dirigido por el profesor Javier Sanz Larruga.

18 A. Embid ORujo (2016), «En la hipótesis de una reforma constitucional, el derecho al medio ambiente debería caracterizarse como derecho fundamental», en J. Ma BAÑo LEÓN (coord.), Memorial para la reforma del Estado. Estudios en homenaje a Santiago Muñoz Machado (t. 1, págs.. 381 y ss.), Madrid: Centro de Estudios Políticos y Constitucionales.

19 El elenco de sus estudios sobre esta materia es amplísimo, por lo que nos limitaremos a citar: L. MaRtín-Retortillo (2006), «La defensa cruzada de derechos: la protección del medio ambiente en la jurisprudencia del Tribunal Europeo de Derechos Humanos», Revista de Administración Pública, 132, págs. 727-746. 
mente ruidos, emisiones u olores susceptibles de afectar a la salud o a la intimidad personal o familiar (SSTC 119/2001, 16/2004 y 150/2011).

La tutela de los derechos fundamentales afectados es, en cualquier caso, una solución in extremis para los particulares afectados por determinadas agresiones ambientales —que se han limitado hasta ahora a los ruidos y olores-, y aunque su ámbito de aplicación pueda ser potencialmente más amplio (pensemos, por ejemplo, en las emisiones de gases contaminantes susceptibles de afectar a la salud), su utilidad para la protección de los intereses ambientales colectivos no deja de ser reducida, al actuar cuando el daño ambiental ya se ha producido y los instrumentos de prevención han fallado. Por otro lado, entre las posibles técnicas concretas de que dispone el legislador para hacer el efectivo el mandato de protección ambiental del artículo $45 \mathrm{CE}$ está, obviamente, el reconocimiento de derechos ambientales subjetivos invocables por los ciudadanos ante los tribunales. Como derechos subjetivos específicamente ambientales se han reconocido ya, por la Ley 27/2006, determinados derechos procedimentales ligados a la información, la participación y el acceso a la justicia impulsados por el Convenio de Aarhus, cuya lesión puede invocarse en muchos casos ante los Tribunales sin alegar derecho ni interés lesionado alguno.

Mucha mayor relevancia reviste, por lo expuesto, contar con un completo sistema jurídico dirigido a la prevención de los daños ambientales. Tal derecho podemos decir que existe hoy en España gracias sobre todo a la incorporación del acervo jurídico europeo.

En una de las manifestaciones más llamativas de la aplicación de la cláusula, de origen norteamericano, de los «poderes implícitos» (prevista ya en el artículo 235 del TCEE), desde los años setenta del siglo pasado la Comunidad Económica Europea comenzó a legislar para la protección del medio ambiente a pesar de la ausencia de toda referencia a esta competencia en los Tratados de Roma. Tras su consagración como uno de los «objetivos esenciales» de la Comunidad por el Tribunal de Justicia (Sentencia de 7 de febrero de 1985, asunto 240/83, Procurador de la República c. Asociación de defensa de la utilización como combustible de aceites usados), y su posterior incorporación al derecho originario por el Acta Única Europea de 1986, las sucesivas reformas de los Tratados no han hecho sino realzar el objetivo ambiental de la Unión Europea, y ésta se ha dotado de un acervo normativo en la materia considerado como uno de los más avanzados y completos del mundo ${ }^{20}$.

20 Sobre el derecho de la protección del medio ambiente en la Unión Europea, el manual pionero fue el de E. Alonso García (1993), El derecho ambiental de la Comunidad Europea, 
Actualmente, el derecho ambiental europeo - y, en su transposición, el nuestro-, se compone de una larguísima cadena de normas, en su gran mayoría directivas, que pueden encuadrarse en dos tipos básicos según su objetivo. En primer lugar, hay una larga serie de directivas o reglamentos de carácter horizontal o transversal, que introducen instrumentos de protección ambiental aplicables en diversos sectores o ámbitos de actividad, tales como: directivas de evaluación de impacto ambiental de proyectos y de planes y programas; directivas para garantizar el acceso al público a la información medioambiental y su participación en la elaboración de los planes y programas ambientales; directiva sobre responsabilidad medioambiental; directiva para la prevención y gestión integradas de la contaminación, reglamentos por los que se regula la etiqueta ecológica de la Unión Europea y el sistema comunitario de gestión y auditoría medioambientales (EMAS). Y, en segundo lugar, existen multitud de regulaciones sectoriales, dirigidas bien a la protección de los distintos recursos (entre otras: las directivas relativas a la calidad de las aguas y la Directiva por la que se establece un marco comunitario de actuación en el ámbito de la política de aguas; directivas para la protección de la naturaleza y la biodiversidad —Directiva AVES y Directiva Hábitat-, y la Directiva relativa a la calidad del aire ambiente y a una atmósfera más limpia en Europa), o bien a la regulación de los agentes contaminantes y de los problemas ambientales concretos (como son, entre otras, las directivas para la prevención de los accidentes industriales, las directivas sobre residuos, las directivas sobre la contaminación causada por distintos afluentes y productos, y otras muchas).

Es interesante observar que, a pesar de que el medio ambiente es una competencia compartida con los Estados miembros (art. 4 del TFUE) y se rige por ello por el principio de subsidiariedad (art. 5 y Protocolo núm. 2 del TUE), el progresivo agravamiento de los problemas ambientales, y la incapacidad de los Estados para solventarlos por sí solos, han llevado a la Unión a legislar en materias que, en principio, por su ámbito territorial o tipo de regulación, parecería que eran más propias de la competencia de los Estados ${ }^{21}$. Muy significativo resulta también que la protección del medio ambiente haya sido uno de los primeros ámbitos

Madrid: Fundación Universidad-Empresa, y actualmente véase, por todos, C. Plaza Martín (2005), Derecho ambiental de la Unión Europea, Valencia: Tirant lo Blanch.

21 Este es el caso de las molestias sonoras (Directiva 2002/49/CE, sobre evaluación y gestión del ruido ambiental), de la responsabilidad por daños ambientales (Directiva 2004/35/ CE sobre responsabilidad en relación con la prevención y reparación de daños ambientales), y, más recientemente, la regulación, para paliar la grave contaminación de muchas ciudades europeas, de las emisiones contaminantes de la atmósfera de las instalaciones de combustión medianas, incluidos los sistemas de calefacción y climatización domésticas o residenciales (Directiva 2015/2193/CE). 
en los que se ha llevado a cabo una armonización de las normas penales de los Estados miembros (Directiva 2008/99/CE del Parlamento Europeo y el Consejo relativa a la protección del medio ambiente mediante el derecho penal), lo que dio incluso lugar a un recurso de anulación interinstitucional ante el TJUE, que este Tribunal resolvió a favor de la competencia de la Unión para legislar en materia penal con el fin de «garantizar la plena efectividad de las normas que dicte en materia medioambiental»(STCE — Gran Sala- de 13 de septiembre de 2005, Comisión c. Consejo, asunto C-176/03).

Para España, la incorporación del acervo jurídico comunitario ha sido determinante para la creación de un moderno derecho ambiental, prácticamente inexistente en 1986, y aún en nuestros días los avances más importantes en este ámbito vienen de la mano del derecho europeo. Hoy puede afirmarse que es una rama del ordenamiento ya consolidada y dotada de principios propios. Se trata, además, de un derecho con poderosa fuerza expansiva, que incide en todas las demás ramas del ordenamiento. Así se manifiesta, en especial, en el derecho urbanístico español que, tras vivir tradicionalmente de espaldas a la perspectiva ecológica, ha incorporado hasta tal punto los condicionantes ambientales que hoy puede decirse que «urbanismo y medio ambiente son —ahora- dos realidades inseparables» ${ }^{22}$. Sobre algunos de los múltiples problemas jurídicos que plantea nuestro derecho urbanístico para garantizar el desarrollo sostenible de un bien escaso como es el suelo he reflexionado en otro número de esta Revista, en un artículo que resultó tristemente premonitorio y al que me remito ${ }^{23}$. Me limitaré aquí a señalar que la Ley 21/2013 de evaluación ambiental ha estipulado que la evaluación del paisaje se lleve a cabo en los términos del Convenio Europeo del Paisaje de Florencia, ratificado por España en 2007, y que obliga a nuestro país a dotarse de medidas efectivas para su protección. Tales medidas, aunque existentes en algunas comunidades autónomas ${ }^{24}$, brillan por su ausencia en la mayoría de ellas y a nivel nacional. Y, sin embargo, la protección del paisaje resulta capital en un país que tiene en el turismo una de sus principales fuentes de ingresos pero que ha degradado algunos

22 J. Ma . Baño León (2009), Derecho Urbanístico Común, Madrid: Iustel, pág. 208, con cita del trabajo de J. Ponce Solé (2008), «Urbanismo y Medio Ambiente: dos realidades jurídicas inseparables», en Derecho Urbanístico del siglo XXI, tomo II, Barcelona: Bosch.

23 B. Lozano Cutanda (2007), "Urbanismo y corrupción: algunas reflexiones desde el derecho administrativo», Revista de Administración Pública, 172, págs. 339-361.

24 Existen así legislaciones muy avanzadas y completas como las de Cataluña (Ley 8/2005, de protección, gestión y ordenación del paisaje), de Galicia (Ley 7/2008, de protección del paisaje de Galicia), y de la Comunitat Valenciana (Ley 5/2014, de Ordenación del Territorio, Urbanismo y Paisaje), y, en contraste, una gran mayoría de comunidades autónomas carecen de normativa específica para la protección paisajística. 
de los lugares más hermosos de sus parajes naturales y, en especial, de sus costas: tan grave o más que lo mucho que se ha edificado en el litoral es la falta de atención a la integración estética de las construcciones en el entorno.

En cuanto a los principios del derecho ambiental, los más asentados se han labrado en el ámbito del derecho internacional y aparecen hoy constitucionalizados en los Tratados de la Unión Europea: el ya citado principio de integración del medio ambiente en las demás políticas de la Unión del artículo 11 del TFUE, y los principios consagrados por su artículo 191.2: principio de "cautela y de acción preventiva», de «corrección de los atentados al medio ambiente preferentemente en la fuente misma», y «quien contamina paga». Pero un «nuevo» principio de protección ambiental ha sido alumbrado recientemente por la doctrina y ha recibido en 2015 su primer reconocimiento importante por el Tribunal Constitucional español. Se trata del principio de no regresión o cláusula de standstill, que proviene del ámbito de los derechos sociales y que ha sido reelaborado y aplicado por la doctrina al derecho ambiental. En palabras de F. LóPEz RAMón, se trata de «una derivación del principio de desarrollo sostenible, que impone un proceso solidario con las generaciones futuras, solidaridad que implica no retroceder nunca en las medidas de protección del medio ambiente ${ }^{25}$. La reciente e importante Sentencia del Tribunal Constitucional 233/2015 ha reconocido que este principio, si bien «es hoy por hoy a lo sumo una lex non scripta en el Derecho internacional», "constituye una formulación doctrinal avanzada que ya ha alumbrado una aspiración política». Tal aspiración aparece formulada con toda claridad en la Resolución del Parlamento Europeo de 29 de septiembre de 2011, sobre la elaboración de una posición común de la UE ante la Conferencia de Naciones Unidas sobre el Desarrollo Sostenible («Río+20»), en cuyo apartado 97 pide «el reconocimiento del principio de no regresión en el contexto de la protección del medio ambiente y de los derechos fundamentales».

En el empeño doctrinal por acuñar la cláusula Standstill late la propia insuficiencia de su postulado matriz, el «desarrollo sostenible», como principio válido u operativo para prevenir los retrocesos legislativos en la conservación y defensa del medio ambiente. En los últimos años se aprecian, en efecto, claros retrocesos en la protección ambiental de nuestro derecho, como consecuencia fundamentalmente de la crisis económica que se inició en 2008 y que dio lugar a la adopción de po-

25 F. LóPEz RAMÓN (2011), «Introducción general: regresiones del derecho ambiental», en el Observatorio de Políticas Ambientales 2011 (págs. 19 y ss.), publicado en la revista Actualidad Jurídica Ambiental. 
líticas que han preterido cualquier interés que no sea la reactivación económica y la creación de empleo, a lo que se ha unido el proceso de liberalización impulsado por las normas de transposición de la Directiva de Servicios y por la Ley 20/2013, de garantía de la unidad de mercado. El legislador ha utilizado además con frecuencia del término «sostenible» para etiquetar normas que poca o ninguna relación guardan con la protección ambiental («Ley de economía sostenible», o "Ley de racionalización y sostenibilidad de la Administración Local»), e incluso una ley que contiene preceptos de carácter claramente regresivo para la tutela de bienes públicos ambientales: como es la Ley 2/2013, de protección y uso sostenible del litoral.

Ha sido precisamente al declarar la inconstitucionalidad y nulidad de algunos de los artículos de esta Ley cuando la STC 233/2015 citada ha dado carta de naturaleza al principio de no regresión ambiental. Los deberes de conservación, defensa y restauración del medio ambiente que el artículo $45 \mathrm{CE}$ impone a los poderes comportan, a decir de nuestro Alto Intérprete constitucional, «tanto la preservación de lo existente como una vertiente dinámica tendente a su mejoramiento» y ello «inevitablemente evoca la idea de "no regresión"». Por mucho que la Sentencia se preocupe por recalcar que este deber «se proyecta sobre el medio físico» mientras que el principio de no regresión «se predica del ordenamiento jurídico» y éste no puede ser nunca intangible, en la práctica ambas dimensiones inevitablemente confluyen, pues una legislación ambientalmente regresiva difícilmente no tendrá una repercusión negativa en el medio físico, incluso a muy corto plazo.

Entendemos, por ello, que el contenido que el Tribunal Constitucional ha otorgado al principio de no regresión, aunque necesitado aún de mayor concreción, se sitúa en la línea ya marcada por la jurisprudencia de exigencia de motivación a las medidas legislativas que supongan un retroceso en la protección ambiental. En efecto, el Tribunal Supremo ha venido aplicando este principio al urbanismo para exigir, cuando se trata de desclasificar un suelo declarado como no urbanizable protegido o introducir un cambio de uso o de localización de zonas verdes, una motivación reforzada ${ }^{26}$.

26 Como indica la STS de 23 de febrero de 2012 (rec. 3774/2009, ponente Rafael Fernández Valverde), «El principio de no regresión en relación a los suelos especialmente protegidos exige e impone un plus de motivación exigente, pormenorizada y particularizada de aquellas actuaciones urbanísticas que impliquen la desprotección de todo o parte de dichos suelos». En el mismo sentido, véase SSTS de 13 de junio de 2011 (rec. 4045) de 29 de marzo de 2012 (rec. 3425/2009) y de 30 de septiembre de 2011 (rec. 1294/2008), comentadas en B. Lozano Cutanda (2012), "Principio Standstill versus Discrecionalidad Administrativa», en E. García DE ENTERRÍA (coord.), Administración y Justicia: un análisis jurisprudencial. Liber amicorum Tomás Ramón Fernández. (págs. 1545 y ss.), Madrid: Civitas. 
De un modo necesariamente más deferente con el legislador democrático, el principio de no regresión de las leyes ahora alumbrado por el Tribunal Constitucional y vinculado al deber de conservación del artículo $45 \mathrm{CE}$, «no consentiría la adopción de medidas, carentes de justificación objetiva, de tal calibre que supusieran un patente retroceso en el grado de protección que se ha alcanzado tras décadas de intervención tutitiva» $\left(\mathrm{FJ} 1^{\circ}\right.$ ). Se trata, en suma, de un reforzamiento del principio de proscripción de la arbitrariedad del art. 9.3 derivado del deber constitucional de conservación que impone a todos los poderes públicos el art. $45 \mathrm{CE}$. Interesa señalar que la propia Sentencia aplica este criterio, cuando, declara la inconstitucionalidad por infracción del artículo 132.2 CE de los apartados 1, 2 y 4 de la disposición adicional cuarta de la ley cuestionada, relativa al deslinde de la isla de Formentera, por considerar que tal deslinde carece de «justificación racional», sin «datos científicos, objetivos y contrastados», que permitan diferenciar este territorio del resto de la costa española.

\section{ANÁLISIS y PROPUESTAS DE MEJORA DE LA LEGISLACIÓN Y DE LA GOBER- NANZA AMBIENTALES}

Entrando ya en un análisis más de detalle del derecho ambiental español, dentro de lo que permite la extensión máxima de este trabajo, el punto de partida ineludible lo constituye el «Análisis de los resultados medioambientales de la OCDE: España 2015» (Informe OCDE-2015 en adelante) que expone de forma muy completa y por sectores los logros y los retos pendientes en el periodo desde el año 2000.

Sorprende, para empezar, por la tendencia al pesimismo que tenemos los españoles, que el Informe ponga de relieve que «España ha llevado a cabo progresos importantes en su comportamiento medioambiental desde el año 2000», y ello en todos los sectores analizados. Sin embargo, también planean sobre todos los ámbitos sombras importantes $^{27}$. El Informe indica la necesidad de introducir diversas medidas

27 Por poner algún ejemplo, en materia de biodiversidad y ecosistemas la conclusión es que «el porcentaje de zonas protegidas se encuentra entre los más altos de la OCDE, con alrededor del 29 por ciento del territorio y el 8,4\% por ciento de las aguas territoriales de España sujetos a alguna forma de protección de la naturaleza» (es una de las cifras más elevadas de la OCDE, que supera los objetivos de Aichi para las zonas protegidas terrestres y está cerca de alcanzarlos para las zonas marinas), pero «con todo, el estado de conservación de cerca del 40 por ciento de los hábitats y de las especies es relativamente desfavorable». Del mismo modo, en materia de calidad de las aguas, si bien el estado ecológico y químico de las masas de aguas superficiales ha mejorado, se pone de relieve que cerca del 30 por ciento de las aguas superficiales presentaban un estado ecológico «moderado» y, en particular, el río Guadiana 
de mejora en el marco regulatorio e institucional con las que por lo general coincido. Me limitaré a exponer las que me parecen más urgentes e importantes.

En primer lugar, considero necesario revisar toda la normativa ambiental vigente con dos objetivos: establecer un marco jurídico suficientemente armonizado y coherente a nivel nacional, que evite la sobrerregulación, y mejorar la calidad de las leyes. Se trataría de acometer, a nivel nacional, un programa del tipo del REFIT de la Unión Europea (Regulatory Fitness and Performarnce Programme), de adecuación y eficacia de la reglamentación. Pero, a diferencia del programa REFIT, no se perseguiría aquí el objetivo de evaluar la necesidad de intervención normativa sino el de simplificar, dotar de coherencia y hacer más eficaz la legislación ambiental existente. Las leyes ambientales no pueden evaluarse atendiendo a un principio coste-beneficio económico, dado que se inspiran muchas veces en el principio de precaución o cautela y sus beneficios a largo plazo (al igual que ocurre con la legislación en materia de seguridad alimentaria o de salud), son difíciles de cuantificar.

Esta revisión se llevaría a cabo, en primer lugar, con el fin de establecer un marco jurídico ambiental suficientemente armonizado y estable, que permita aplicar las exigencias ambientales de modo coherente en todas las regiones. Suscribimos en este punto la afirmación del Informe OCDE-2015 de que si bien la descentralización del sistema español en cuanto a la gestión ha permitido que las medidas adoptadas se ajusten a las necesidades locales, por otro lado «ha dificultado el establecimiento de un marco coherente para el medio ambiente, que sea capaz de abordar las ambigüedades, desfase e incoherencias en las funciones y responsabilidades institucionales, y para la aplicación de las exigencias medioambientales de modo coherente en todas las regiones».

Según mi experiencia, este fenómeno se agudiza en aquellos sectores en los que no existe normativa europea y el Estado ha renunciado o postergado la aprobación de una legislación básica. Un ejemplo muy claro de esta situación y de los problemas que plantea lo tenemos en las licencias o informes previos para las instalaciones o actividades susceptibles de incidir en el medio ambiente del municipio. Ante el retraso del legislador estatal, que se ha convertido en olvido, en aprobar una nueva legislación básica en la materia que sustituyera al vetusto RAMINP, las comunidades autónomas fueron aprobando leyes sobre el control previo municipal de las actividades con incidencia ambiental, pero los tribuna-

mostraba «un grado de contaminación elevado, con hasta un 70 por ciento de sus aguas en estado "moderado"». 
les seguían considerando que sus normas resultaban aplicables como legislación básica ${ }^{28}$, en especial la que establece que las nuevas instalaciones que puedan ser consideradas molestas o insalubres deberán situarse a una distancia mínima de 2.000 metros del núcleo de población más cercano. Se trataba de una regla muy sencilla de aplicar a la hora de autorizar una nueva industria o actividad potencialmente lesiva para el medio ambiente urbano, lo que sin duda explica el apego que le han mostrado los tribunales ${ }^{29}$.

La regla de las distancias del RAMINP ha sobrevivido así, contra viento y marea, hasta su derogación expresa, que aprobaron primero algunas leyes autonómicas para sus ámbitos territoriales y generalizó después la Ley 34/2007 de calidad del aire y protección de la atmósfera, aunque con una curiosa fórmula prospectiva que permitió que siguiera en vigor en las comunidades autónomas que no tuvieran aprobada normativa propia en la materia (todas lo han hecho ya). Sin embargo, ante la ausencia de legislación básica estatal, las regulaciones autonómicas que han venido a sustituir a la licencia de actividades clasificadas contienen regulaciones enormemente dispares: en algunas se mantiene el sistema tradicional ${ }^{30}$; en otras se ha sustituido por un trámite de evaluación o informe ambiental que se inserta dentro del procedimiento de autorización municipal de apertura o de actividad ${ }^{31}$, y hay, por último, algunas que directamente han suprimido este sistema de control previo ambiental. Un caso extremo, y no el único, de supresión de la técnica del control previo municipal de las actividades molestas o insalubres es el de Castilla-La Mancha, pues la Ley 8/2014, de 20 de noviembre, de Comercio derogó el RAMINP sin sustituirlo por ningún otro procedimiento o informe, de tal suerte que es necesario acudir a la legislación sectorial y a las ordenanzas locales para determinar en cada caso concreto si existe alguna regulación por el tipo

28 Por aplicación de la doctrina del Tribunal Constitucional de que la comunidad autónoma «no está obligada a esperar la legislación básica post-constitucional, pero sus disposiciones legales o de rango inferior deberán respetar en todo caso no solo los principios que inmediatamente se derivan de la Constitución sino también las bases (en sentido material) que se infieran de la legislación preconstitucional» (SS. 32/1981 y 1/1982).

29 Todavía en el año en que se escriben estas líneas, una Sentencia del Tribunal Supremo ha anulado un proyecto de gran envergadura, la Planta de almacenamiento y regasificación de gas natural de ENAGAS en el Puerto de El Musel (Gijón), porque al iniciarse el procedimiento autorizatorio no había entrado todavía en vigor la Ley autonómica que desplazó al RAMINP en el ámbito de la Comunidad Autónoma de Asturias (STS de 29 de febrero de 2016, rec. 457/2016).

30 Por ejemplo, la Ley 7/2011, de actividades clasificadas y espectáculos públicos de Canarias o el Capítulo III dedicado a las «actividades clasificadas» de la Ley 3/1998, general de protección del medio ambiente del País Vasco.

31 Por ejemplo, la «evaluación de incidencia ambiental» de Galicia (Ley 1/1995, de Protección Ambiental de Galicia y Decreto 133/2008), o «comprobación ambiental» de Cantabria (Ley 17/2006, de Control Ambiental Integrado y Decreto 19/2010). 
de actividad; de no ser así bastará con presentar una declaración responsable para iniciar su puesta en marcha.

Una norma tan modesta como la regla de los 2.000 metros otorgaba seguridad jurídica al operador económico y facilitaba su control administrativo y, en su caso, judicial. Es cierto, como afirma la Exposición de Motivos de la Ley 8/2014 de Castilla-La Mancha citada, que hoy existe una «amplia normativa sectorial en materia sanitaria, ambiental, agroalimentaria, técnico-industrial, urbanística, de ordenación del territorio, turística y de espectáculos y establecimientos públicos y recreativos», pero no necesariamente tan abigarrado conjunto de normas es capaz de garantizar una cosa tan simple como es que las actividades se desarrollen sin causar riesgos o molestias a los vecinos.

La ausencia por completo de un marco coherente o armonizado se aprecia también en otros sectores, como el ya señalado de la protección del paisaje o el de la tributación ecológica. Este último es un sector especialmente deficiente pues, como pone de manifiesto el Informe OCDE-2015, los ingresos derivados de los impuestos medioambientales «se encuentran entre los más bajos de los miembros de la OCDE pertenecientes a la UE».

En este campo, la pasividad del legislador estatal por establecer impuestos de ordenación con una finalidad ambiental contrasta con los heterogéneos impuestos que llevan la «etiqueta ecológica» en las comunidades autónomas, con el resultado de una auténtica «maraña» de gravámenes ambientales o pretendidamente ambientales. Los tributos autonómicos más numerosos e importantes son los que gravan la emisión por las industrias y actividades de determinados gases nocivos ${ }^{32}$, pero se han creado, además, otros muchos tributos de carácter ambiental. Algunos de ellos inciden sobre elementos ya gravados por el Estado, como ocurre singularmente con las exacciones o cánones autonómicos sobre el agua ${ }^{33}$; en otros casos, la fiscalidad ambiental autonómica se adelanta y sirve de acicate a la creación por el Estado de nuevos modelos de fiscalidad ambiental ${ }^{34}$.

32 Entre otros, el impuesto gallego sobre la contaminación atmosférica, el impuesto sobre emisión de gases a la atmósfera de Andalucía, el impuesto aragonés sobre el daño ambiental causado por la emisión de contaminantes a la atmósfera, o el impuesto sobre determinadas actividades que inciden en el medio ambiente de Castilla-La Mancha.

33 Ello ha hecho necesaria la introducción de una previsión específica en el Texto Refundido de la Ley de Aguas para evitar que se produzca la doble imposición con el canon estatal de control de vertido: artículo 113.8 del Texto Refundido de la Ley de Aguas, introducido por la Ley $11 / 2005$.

34 Así ocurre, por ejemplo, con el impuesto sobre las bolsas de plástico de un solo uso de Andalucía, que posiblemente tendrá que generalizarse cuando se transponga la Directiva 2015/720/UE en la que se indica que «las medidas que tomen los Estados miembros pueden incluir el uso de instrumentos económicos como los precios, los impuestos y las tasas, que 
Pero hay, además, toda una larga ristra de impuestos ecológicos pintorescos, cuya finalidad ambiental, como ha puesto de relieve la doctrina, resulta en algunos casos más que dudosa. Sin embargo, el mero hecho de que un impuesto no cumpla una finalidad ambiental a pesar de autocalificarse como impuesto ecológico no es motivo suficiente para declarar lo contrario a la Constitución o al derecho comunitario, para ello es preciso que resulte contrario a los derechos y principios constitucionales en materia tributaria o a alguna disposición de la Unión Europea. Por esta razón, rara vez prosperan los recursos contra los tributos falsamente ambientales ${ }^{35}$, aunque en un caso extremo como es el impuesto sobre la producción de energía eólica de Galicia y Castilla y León, tras varias sentencias desestimatorias de los recursos interpuestos, finalmente el Tribunal Superior de Justicia de Castilla-La Mancha ha elevado una cuestión prejudicial de interpretación ante el TJUE en la que se pregunta si siendo los tributos ecológicos un instrumento de incentivo negativo, su aplicación podría resultar contraria a Directiva 2008/09/CE, de fomento del uso de energías renovables (Auto n ${ }^{\circ}$ 179/16 de 8 de abril de 2016).

Ante esta situación, el Informe de la Comisión de Expertos para la reforma del sistema tributario español, el conocido como Informe Lagares de 2014 (disponible en Internet) propuso ya simplificar, consolidar y reformar los impuestos medioambientales, indicando las líneas que debería seguir esta reforma (cuyo núcleo duro debería ser «una modificación profunda de la fiscalidad sobre la energía»), y el Informe de la OCDE-2015 vuelve a incidir en ello, poniendo de relieve que la aplicación de esta reforma «exigiría una coordinación estrecha entre el gobierno central y las comunidades autónomas».

Pero si el desordenamiento jurídico ambiental resulta especialmente acusado en sectores, como los expuestos, que adolecen de legislación básica, cuando ésta existe los problemas no son menores como consecuencia de la elevada conflictividad que genera la distribución de competencias normativas en la materia.

han demostrado ser particularmente eficaces para reducir el consumo de bolsas de plástico» (cdo. 11).

35 El Tribunal Constitucional declaró inconstitucionales y nulos algunos tributos ecológicos por vulnerar el sistema constitucional de distribución de competencias en relación con la cláusula estatal que prohíbe la doble imposición con los tributos locales e hizo una dura crítica de su carácter falsamente ambiental (SS. 289/2000 y196/2012). El legislador vino, sin embargo, a flexibilizar la prohibición de la doble imposición mediante la previsión contenida en el artículo 6.3 de la Ley Orgánica de Financiación de las Comunidades Autónomas: ahora es preciso que afecten al mismo «hecho imponible», concepto mucho más estricto que el de «materia imponible» contenido en la redacción anterior, con lo que la anulación de un tributo por esta causa resulta difícil. 
La Constitución atribuye al Estado la facultad de dictar «la legislación básica sobre protección del medio ambiente, sin perjuicio de las facultades de las comunidades autónomas de establecer normas adicionales de protección» (artículo 149.1.23). Como en todos los ámbitos en los que la delimitación de competencias se asienta sobre el binomio bases-desarrollo, el concepto de lo básico ha experimentado una evolución en la jurisprudencia constitucional, y de una construcción inicial principialista de lo básico se evolucionó muy pronto hacia un entendimiento muy amplio, en virtud del cual «el constituyente no ha pretendido reservar a la competencia legislativa del Estado sólo el establecimiento de criterios básicos necesitados de ulterior desarrollo, sino que, por el contrario, ha entendido que había de ser el Estado el que estableciese toda la normativa que considerase indispensable para la protección del medio ambiente»(S. 149/1991), con el límite de que legislación básica estatal no pueda llegar «a tal grado de detalle que no permita desarrollo legislativo alguno de las comunidades autónomas con competencias en materia de medio ambiente» (STC 102/1995).

Esta interpretación constitucional de lo básico se ha visto potenciada por las exigencias derivadas de una transposición de las directivas europeas que garantice su efecto útil, dando por resultado el actual reconocimiento de una amplia capacidad del Estado para su determinación, tanto con normas legales como reglamentarias y con independencia del grado de detalle de la regulación. Hay que señalar que, con frecuencia, la minuciosidad de la regulación básica estatal resulta ineludible por el propio tecnicismo y concreción de las normas ambientales: ningún desarrollo puede hacerse, por ejemplo, como no sea la fijación de estándares más rigurosos de protección, a los preceptos estatales que establecen, en aplicación de una Directiva europea, cuáles son los valores límite de las emisiones o vertidos de determinados agentes contaminantes.

Pues bien, esta delimitación de la legislación básica en materia ambiental llevada a cabo por el Tribunal Constitucional no es fácilmente aceptada por los actores políticos y las comunidades autónomas con una concepción más descentralizada o federal del Estado, lo que da lugar a una altísima conflictividad competencial (como lo muestra el que más de la mitad de las normas estatales en la materia sean recurridas por las autonomías ante el TC). Pero más grave aún que los conflictos competenciales es el hecho de que se mantengan o se aprueben normas autonómicas contrarias a la legislación básica y que no constituyen normas adicionales de protección.

Especial resistencia suscita la adecuación autonómica a la regulación por el Estado de un modelo procedimental común, aun en los casos 
en que ello resulta imprescindible para garantizar la transposición uniforme y el efecto útil de una Directiva europea. Un ejemplo notorio lo tenemos en la legislación básica sobre evaluación de impacto ambiental, sin duda la técnica estrella de prevención. Si algún avance supuso la Ley 21/2013 de evaluación ambiental, muchos de cuyos preceptos introducen claras regresiones en la protección ambiental (basta comparar el anexo I de esta Ley con el del anterior Texto Refundido de Evaluación de Impacto Ambiental: no son pocos los proyectos de obras y actividades para los que se ha suprimido el sometimiento en todo caso a evaluación ambiental ordinaria ${ }^{36}$ ), fue el de introducir una regulación única, y siguiendo el mismo esquema, de los dos procedimientos de evaluación ambiental: el de proyectos y el de planes y programas. Con el fin de lograr que este marco jurídico armonizado, al que se le otorga el carácter de legislación básica y que está inspirado por lo demás en algunas regulaciones autonómicas (como ocurre con la ahora denominada «evaluación ambiental simplificada»), se implantase efectivamente en todo el territorio nacional, la Ley reguló un novedoso sistema de entrada en vigor: otorgó el plazo de un año para que las comunidades autónomas que han legislado en la materia (prácticamente todas) pudieran adaptarse a sus preceptos y dispuso que, a partir de ese momento, «en cualquier caso, serán aplicables los artículos de esta ley, salvo los no básicos, a todas las comunidades autónomas» (disp. final undécima).

Sin embargo, sobrepasado este plazo, aún hay comunidades autónomas que mantienen el sistema anterior o que, han aprobado nuevas leyes con un esquema procedimental distinto y que en algún caso hace incluso difícilmente reconocible la técnica, al modificar la denominación que se utiliza a nivel nacional y europeo ${ }^{37}$.

El «desordenamiento jurídico ambiental» resultante de esta falta de homogeneidad normativa es contrario al principio fundamental de la seguridad jurídica y a los postulados ambientales, por cuanto falta una «regulación de mínimos» sobre la protección ambiental. Pero, además,

36 Véase B. Lozano cutanda y Z. Olano Rodríguez (2014), «Ley 21/2013, de evaluación ambiental: Novedades en el ámbito de aplicación (comparativa de los anexos)», disponible en: http://www.gomezacebo-pombo.com/media/k2/attachments/ley-21-2013-de-evaluacion-ambiental-novedades-en-el-ambito-de-aplicacion-comparativa-de-los-anexos.pdf.

37 Este es el caso de la Ley 3/2015 de Andalucía, que a pesar de hacer referencia en su Exposición de Motivos a la «inexcusable adaptación a la Ley 21/2013», mantiene el modelo anterior, en el que la evaluación ambiental se integra con otros pronunciamientos ambientales exigibles con carácter previo en la denominada «autorización ambiental unificada». La integración con otros procedimientos es, ciertamente, de una de las posibilidades ofrecidas por la Directiva 9011/92/UE, pero si la legislación básica ha optado por regularlo separadamente, el introducir otro sistema dificulta la aplicación de esta técnica a nivel nacional e incluso, en este caso, la hace difícilmente reconocible, al suprimirse su propia denominación como «evaluación de impacto ambiental» o «evaluación ambiental». 
aumenta las cargas y costes administrativos y dificulta la unidad de mercado, y con ello la actividad económica, al tener que seguir las empresas que operan en todo el territorio nacional procedimientos distintos según la autonomía o incluso el municipio en que vayan a desarrollar una actividad y al ser también diferentes las limitaciones o cargas que se aplican a su funcionamiento. Así lo pone de manifiesto la Comisión de Medio Ambiente, Salud Pública y Seguridad Alimentaria en su Opinión para la Comisión de Asuntos Jurídicos sobre el programa REFIT (disponible en Internet): «Destaca que el 32 por ciento de las cargas administrativas que tienen su origen en la UE son consecuencia de la decisión de algunos Estados miembros de ir más allá de lo que exige la legislación de la UE (sobrerregulación) y de la ineficacia de sus procedimientos administrativos; considera, por tanto, que resulta esencial evitar la «sobrerregulación», es decir, la introducción, durante la fase de transposición de directivas de la UE, de procedimientos y cargas ulteriores con respecto a los definidos por la legislación de la Unión Europea; la sobrerregulación aumenta la complejidad y los costes que soportan las autoridades locales y regionales y las empresas públicas y privadas [...]».

Lo que se propone, por ello, es que, la revisión de la legislación ambiental se haga partiendo del postulado de que la legislación básica no solo puede regular, como resulta ya de la doctrina constitucional, sino que debe regular todo lo indispensable para garantizar la garantía de unos mínimos uniformes de protección en cada sector afectado por este ordenamiento, incluido el modelo procedimental a seguir y sin perjuicio de la posibilidad de que las comunidades autónomas, respetando el esquema común, puedan introducir normas o parámetros adicionales de protección. A las comunidades autónomas les corresponde asimismo, y ello es una atribución fundamental en esta materia, la competencia exclusiva de ejecución (reconocida por el Tribunal Constitucional salvo en supuestos excepcionales), lo que conlleva el deber correlativo de asegurar la aplicación efectiva de la legislación.

Al propio tiempo, el legislador estatal debe ser especialmente cuidadoso para evitar que la vis expansiva del título competencial del medio ambiente conduzca a un progresivo vaciamiento de las competencias autonómicas conexas. Así ocurre cuando se trata de las competencias autonómicas con incidencia territorial, particularmente las relativas a la ordenación del territorio y urbanismo ${ }^{38}$.

38 En estos casos, de acuerdo con la doctrina del Tribunal Constitucional, deben aplicarse mecanismos de cooperación y de coordinación de las Administraciones competentes, y en caso de conflicto, el criterio más adecuado, dentro de su inevitable imprecisión, es el teleológico, «de tal forma que solo las normas estatales cuyo objetivo directo e inmediato sea la protección 
Pero, además de ser mínimamente uniformes, las leyes ambientales han de reunir obviamente unos requisitos de calidad normativa para resultar efectivas. Se diría que a una realidad compleja, como es la protección del medio ambiente, debe corresponderle un ordenamiento asimismo complejo, y ciertamente es así. Pero es que el derecho ambiental que tenemos no solamente es complejo sino confuso, desordenado y muchas veces incompleto. Resulta, en especial, alarmante el cumplimiento tardío y defectuoso de las directivas europeas en la materia. Como señala el Informe de la OCDE-2015, «muchas veces la incorporación de las directivas ha sido tardía, y no ha dado como resultado un cuerpo de legislación medioambiental coherente e integral». Como consecuencia de ello, «entre 2007 y 2013 el número de procedimientos de infracción contra España estuvo por encima de la media de la UE. En 2012 y 2013, España superó a todos los miembros de la UE en cuanto al número de procedimientos con un 11 y un 8 por ciento del total respectivamente».

En vez de incorporar y adaptar a nuestro derecho los preceptos de las directivas, como exige esta forma de legislación bifásica, con frecuencia el legislador español se limita a copiarlas literalmente y no las completa o desarrolla, con las consiguientes lagunas y dudas interpretativas que ello genera. Volviendo al ejemplo de la evaluación de impacto ambiental, resulta sorprendente que a día de hoy todavía no se haya regulado un procedimiento específico para la evaluación de las zonas de la Red Natura 2000. El artículo 6 de la Directiva Hábitat ha sido transpuesto a nuestro Derecho por la Ley 42/2007, del Patrimonio Natural y la Biodiversidad (capítulo III), pero, por lo que respecta a la evaluación que requieren los lugares de la Red Natura 2000, la regulación de la legislación básica estatal se limita a aplicarle la dictada para transponer las directivas de evaluación ambiental de proyectos y de planes y programas, sin más prescripciones específicas que las relativas a su ámbito de aplicación y las que resultan de la transcripción literal del citado precepto de la Directiva. Sin embargo, como resulta de la jurisprudencia del TJUE, pese a su proximidad, las obligaciones de evaluación que se derivan de las directivas sobre las aves y sobre los hábitats son singulares y algunas de sus prescripciones difieren de las del procedimiento de evaluación ambiental ordinario (STJCE de 23 de marzo de 2006, Comisión c. República de Austria, asunto C-209/04) ${ }^{39}$. Esta deficiente legislación básica,

del medio ambiente pueden afectar legítimamente a las competencias autonómicas conexas» (doctrina sentada por la STC 102/1995 y reiterada por otras muchas, como, de modo reciente, por la STC 141/2014).

39 Consciente de esta laguna legal, que no ha sido subsanada por las escasas (y en algunos casos desafortunadas) regulaciones autonómicas en la materia y que ha generado conflictividad en los tribunales, la Ley 6/2010 introdujo en el entonces vigente Texto Refundido de Eva- 
unida a la insuficiente protección dispensada a los Lugares de Importancia Comunitaria (LIC) en muchas comunidades autónomas, explica que, según concluye el Informe de la OCDE-2015, un 40 por ciento de los hábitats de la Red Natura 2000 «son inestables y están en retroceso, y la situación de sus especies típicas está en peligro».

La calidad de las leyes, siempre necesaria para la garantía de la seguridad jurídica, resulta capital cuando se trata de establecer un sistema normativo con el que se tratan de conciliar numerosos intereses cruzados: los intereses ambientales y los vinculados al desarrollo económico, pero también los intereses generales ambientales con los intereses de particulares o empresas y estos últimos entre sí. Las lagunas y contradicciones de la norma son los intersticios por donde penetra el incumplimiento. Interesa en este punto señalar que una mejor regulación ambiental no solo protege mejor nuestros activos naturales, sino que proporciona un marco estable que favorece la inversión y otorga, también, mayor seguridad jurídica a los responsables de adoptar las decisiones. En especial, el severo castigo penal de los delitos ambientales mediante normas penales en blanco y la configuración de los tipos delictivos como delitos de peligro, unida a este carácter complejo y fragmentado de la legislación ambiental, resulta una combinación muy peligrosa tanto para los operadores jurídicos como para los propios responsables políticos ${ }^{40}$.

Por todo lo expuesto, como dice el Informe de la OCDE-2015, «el marco jurídico ambiental sigue necesitado de una revisión en profundidad [...] La reforma del sistema legal en materia de medio ambiente en España debería evitar arreglos legales ad hoc y avanzar hacia el establecimiento de un mecanismo estable de mejora reglamentaria que permita consultas amplias en el seno del gobierno y con otros sectores clave interesados». Se sugiere, en este sentido, el desarrollo de un Código Medioambiental para sistematizar las numerosas normas que regulan de forma separada los distintos ámbitos del medio ambiente (aguas, residuos, aire). Es curioso señalar que ya lo postulaba así la Ley de Protección atmosférica de 1973, pero ello no parece, a día de hoy, ni necesario para revisar la legislación, que bien podría hacerse por secto-

luación de Impacto Ambiental una disposición adicional por la que se habilitaba al Gobierno para que adoptase un reglamento en la materia para establecer «los requisitos adicionales y la metodología que deba utilizarse en la evaluación de impacto ambiental de los proyectos de la Administración del Estado que puedan afectar de forma apreciable a los espacios protegidos de la Red Natura 2000 [...]». Pues bien, esta regulación no solo no se ha llevado a cabo sino que la Ley 21/2013 ha suprimido la habilitación normativa al Gobierno para dictarla.

40 Véase B. Lozano Cutanda (2016), «La potestad sancionadora de la Administración y su adecuada articulación con los delitos administrativos. Una cuestión pendiente», en J. M ${ }^{\mathrm{a}}$ BAÑo LEón (coord.), Memorial para la reforma del Estado. Estudios en homenaje a Santiago Muñoz. Machado (págs. 2837 y ss.), Madrid: Centro de Estudios Políticos y Constitucionales. 
res, ni conveniente, dado que el derecho ambiental, en constante cambio y expansión, no resulta fácilmente codificable. Los avances tecnológicos no dejan de plantear nuevos retos y desafíos a los que debe dar una rápida respuesta el derecho. Por citar un ejemplo de «dilema jurídico ambiental» reciente y aún no pacificado: ¿sí o no a la fractura hidráulica? Y, como posibles problemas inminentes que exigirán un tratamiento jurídico, se nos ocurren los que pueden suscitar los vehículos eléctricos (puntos de carga, recogida y tratamiento de las baterías de litio), o los que se plantearán muy pronto como consecuencia de las posibilidades de exploración de todo tipo de minerales a gran profundidad en el mar (que ya se han suscitado en relación a los hidrocarburos).

Importa destacar, por último, que la revisión y mejora del derecho ambiental es, desde luego, tarea urgente e importante, pero de nada servirá sin otras dos condiciones esenciales para la existencia de un buen gobierno o gobernanza ambiental: unos órganos administrativos especializados dotados de independencia y de medios económicos suficientes, y un sistema judicial que garantice de forma rápida y efectiva su aplicación. Ninguna de las dos condiciones se cumple satisfactoriamente en nuestro país, lo que convierte a buena parte de las leyes ambientales en papel mojado. La OCDE propone, por ello, reforzar el marco institucional con la creación de una Agencia de Medio Ambiente que proporcione apoyo técnico al trabajo del MAGRAMA y mejore la coordinación de las actividades de vigilancia medioambiental. Y, ¿por qué no crear una Agencia Nacional Ambiental independiente de cualquier ministerio, siguiendo el modelo norteamericano? El carácter absolutamente transversal de la legislación ambiental y la necesidad de dotar de auténtica independencia a los responsables de esta política así parecen postularlo.

La falta de medios es otra de las causas de la poca o nula efectividad de muchas políticas ambientales. Así se manifiesta con especial gravedad en los espacios naturales protegidos, pues la declaración de un parque no va siempre precedida, como exige la ley, por la aprobación de un Plan de Ordenación de los Recursos Naturales (PORN) debido a los costes que ello supone, tanto por el pago de expropiaciones e indemnizaciones como por la implantación de políticas de gestión, e incluso muchas veces su aprobación se demora años, con la consiguiente inseguridad jurídica que ello conlleva. Con la crisis económica y la actual política de riguroso control del déficit, los problemas presupuestarios se han agravado, y se han quedado en la cuneta proyectos muy interesantes como, por ejemplo, el inicio en la primera década del siglo por el Ministerio de Medio Ambiente de una política pública de «comprar para proteger» en la costa, similar a la que lleva en Francia el Conservatoire des 
Espaces Littoraux et des Rivages Lacustres que (según información de su página web), cuenta actualmente con «166.305 hectáreas preservadas, esto es, 1.450 kilómetros de costa (13 por ciento de la línea costera)». La solución más sencilla y de carácter permanente a la falta de medios sería adscribir lo recaudado por las multas administrativas ambientales a fines de protección, con lo que se evitaría además un posible uso desviado de la potestad sancionadora como medio para recaudar. Existe, sin embargo, una férrea oposición del Ministerio de Hacienda a la ruptura del principio de caja única, lo que ha limitado esta medida a algunos casos anecdóticos en las comunidades autónomas, pero lo cierto es que esta adscripción sería jurídicamente posible y ya existe un precedente en materia de tráfico ${ }^{41}$.

Y, por último, una brevísima referencia a la Justicia. La elevada conflictividad que caracteriza al derecho ambiental convierte al sistema jurisdiccional en la clave de bóveda del sistema, y en nuestro país los tribunales ordinarios, sobre todo a partir de la década de los ochenta, han hecho mucho por la defensa del medio ambiente, controlando tanto a los operadores económicos como a las propias Administraciones (y, en el caso del Tribunal Constitucional, declarando la inconstitucionalidad de leyes regresivas o de convalidación de medidas anuladas por los tribunales), pero es obvio que los problemas que la aquejan, en los que no nos podemos detener aquí, lastran su efectividad. En materia ambiental, resulta ya un tópico insistir en la importancia de las medidas cautelares, que vienen casi impuestas por el principio homónimo de cautela. En el Informe de la OCDE-2015 se denuncia que «debido a la ineficacia de los medios en los casos de medidas cautelares y amparo judicial y/o la duración de los procedimientos prolongados, varios asuntos han sido "ganados en los tribunales, pero perdidos en la práctica"; así, aunque los jueces han anulado determinados proyectos, las sentencias se han dictado cuando el proyecto ya estaba iniciado». Se citan como ejemplos en este sentido los casos de la construcción de la circunvalación de Madrid M-30 y del hotel Algarrobico, en Almería, aunque, en este último caso, varias sentencias del Tribunal Supremo de 14 de marzo de 2016 lo han declarado definitivamente ilegal y condenado a la demolición: una señal de que luchar por la preservación de nuestros activos ambientales es todavía posible.

41 La Ley 18/2009 incluyó en la Ley sobre Tráfico, Circulación de Vehículos a Motor y de Seguridad Vial la obligación de destinar «íntegramente» el importe de las sanciones económicas obtenidas por infracciones en el ámbito de la Administración General del Estado a la financiación de seguridad vial, prevención de accidentes de tráfico y ayuda a las víctimas (disposición adicional cuarta). 